\title{
A pilot study to determine the effect of one physical therapy session on physical activity levels for individuals with chronic low back pain
}

\author{
Wayne Brewer ${ }^{{ }^{*}}$ (D, Brian T. Swanson ${ }^{2}$, Toni S. Roddey ${ }^{3}$, Habeeblai Adewale $^{4}$, Caleb Ashmore ${ }^{4}$, Jennifer Frerich ${ }^{4}$, \\ Cory Perrin ${ }^{4}$ and Alexis Ortiz ${ }^{3}$
}

\begin{abstract}
Background: A pilot study was conducted to quantify the effect size of changes in physical activity after of one session of physical therapy for individuals with chronic low back pain and to determine factors that predict daily sedentary activity time.

Methods: Fourteen subjects with at least 3 days of physical activity accelerometer data were analyzed before and after one session of physical therapy. Data was analyzed using 1-tailed, paired t-tests with level of significance set at 0.05. Effect sizes were computed using the baseline and post intervention mean differences divided by the baseline and post-intervention differences in the standard deviation.

Results: A nonsignificant reduction in steps-per-day and time spent performing sedentary activities, with increases in light and moderate-vigorous physical activity were found (effect size: $0.15-0.33$ ). A nonsignificant decrease in daily sitting and standing time 1 week immediately following the physical therapy session and an increase in daily lying time ( $p=0.03$ ) (effect size: $0.23-0.69$ ) were found.
\end{abstract}

Conclusion: One physical therapy session resulted in a small physical activity change for individuals with chronic low back pain. Baseline and post intervention levels of pain catastrophisation and perceptions of disability need to be explored in future studies to determine if these are factors that influence levels of physical activity change for these individuals Results are limited by the small sample size, however the ability to increase physical activity in this population may be of clinical relevance.

Trial Registration NCT02823756; June 30, 2016: Retrospectively Registered

Keywords: Chronic low back pain, Physical activity, Physical therapy

\section{Background}

Low back pain (LBP) is a musculoskeletal problem that will affect approximately $80 \%$ of the population at some point of their lives [1] with an estimated unadjusted point prevalence ranging from 6.3 to 56.0 percent [2]. The impairments associated with LBP may progress

\footnotetext{
*Correspondence: Wbrewer@twu.edu

${ }^{1}$ Texas Woman's University, 6124 Institute of Health Sciences-Houston, 7600 Fannin Street, Houston, TX 77030, USA

Full list of author information is available at the end of the article
}

to disability if they continue into a chronic state [3, 4]. Chronic low back pain (CLBP) is often due to repetitive overuse disorders but can also occur as the result of a one-time traumatic injury such as a fall or accident [5]. The continual disability suffered by individuals with CLBP is multifactorial. Vlayen and Linton noted that the fear avoidance model may partially explain why CLBP results in persistent disability for these individuals, due in part to increased pain catastrophizing and fear of movement [6]. Typically fear leads to hypervigilant behaviors 
to protect the individual from engaging in physical activities that are perceived as threatening [6, 7]. The result is the avoidance of necessary physical movements, normally used to perform instrumental activities of daily living. It was hypothesized that this lack of daily movement may lead to a continual cycle of elevated fear, catastrophizing, perceptions of disability, physical disuse and pain [6, 7].

Physical therapy (PT) is an integral component for the functional recovery of individuals with CLBP. Restoration of muscular strength, flexibility, spinal mobility and cardiovascular endurance are typically included in PT regimens designed to improve the function of individuals with CLBP [8]. Often these treatment programs are based on movement classification systems that attempt to categorized patients into distinct treatment paradigms such as: centralization/directional preference exercise, stabilization exercise, traction or manipulation based on factors including: the chronicity of the injury, presence of peripheral neurological symptoms, pain location, and provocation factors $[8,9]$. In practice, there are many instances where the patients' classification is unclear and has a non-specific pathoanatomical etiology that is hallmarked by recurrence of symptoms that often is debilitating [8]. Non-specific low back pain may be addressed with more than one treatment paradigm. A previous study by [10] found that only $50 \%$ of patients fit the described categories, with $25 \%$ fitting more than one category, and $25 \%$ not fitting any of the defined treatment classifications. This classification may be particularly difficult in individuals with longer duration of LBP [11]. Despite the lack of evidence for a standardized exercise prescription for individuals with CLBP, the use of progressive graded exercise has been shown to increase physical activity $[12,13]$. No published studies have examined if physical activity patterns are altered after one session of exercise training for individuals with CLBP.

Spinal manipulation has been shown to have mild to moderate short-term improvements on perceptions of pain and disability that can occur after one treatment session [14]. The proposed rationales for these improvements include a wide range of effects, such as neurophysiological changes, increased segmental joint mobility, and placebo effects from the procedure [15]. Despite these reported benefits, spinal manipulation, which has been shown to be highly effective for individuals with acute low back pain, appears to be less effective for individuals with subacute and chronic low back pain $[8,14,16]$. However, previous studies that have assessed the effectiveness of spinal manipulations used subjective reports of pain and self-perceived levels of disability $[14,16]$. The impact of spinal manipulation on objective measures of physical activity is not clear when performed on a CLBP population.
There are a multitude of patient misconceptions regarding the effectiveness of diagnostic and treatment modalities that are utilized in the medical model such as advanced imaging, opiate use, analgesic/anti-inflammatory injections and surgical procedures [17-20]. Strong, documented evidence for any of these diagnostic and treatment interventions is lacking and frequently these procedures are palliative in nature $[19,20]$. Accordingly, education is considered to be of paramount importance for individuals with CLBP [21]. Patient education delivered in the context of PT interventions typically focuses on three key areas: (1) addressing the fear avoidant behaviors displayed by the patient; (2) informing the patient regarding basic pain science principles; and (3) applying cognitive behavioral approaches such as graded activity and graded exposure programs to promote confrontation with the perceived threat to the patient's wellbeing $[6,13,22]$. These educational methods are often combined with biomechanical principles to promote safe activity performance to prevent re-exacerbation of symptoms. Patient education that utilize cognitive behavioral approaches are often combined with other interventions and are dispersed over several treatment sessions that use patient self-perceptions of pain and disability as the outcomes studied [21, 23-26]. To date, there are no studies that examined if there are immediate changes in physical activity patterns for individuals who receive an initial session of PT that is comprised of patient education.

Despite the myriad of rehabilitative and medical interventions used to address the pain, impairments and resultant disabilities for individuals with CLBP, the documented effectiveness for any one treatment paradigm is lacking $[17,27]$. CLBP is often viewed as recalcitrant to interventions [1, 8, 20, 28]. Most published studies utilize self-perceptions of pain and disability as the primary endpoint [29]. Others use the aforementioned measures combined with physical performance measures such as walking tests, handgrip strength, muscular strength and spinal mobility assessments [30]. While there are published studies that examine the levels of physical activities (PA) for these patients using reliable methods for PA monitoring such as accelerometry, the majority of these studies have occurred outside the clinical environment [31-38]. Accelerometry uses small devices worn on the hip or wrist that measure movement, change of position, steps per day and energy expenditure for a given time period [39-42]. The accuracy of accelerometers far exceeds self-reported questionnaires of PA which often suffer threats to validity such as recall bias [43-45].

When assessed via accelerometer, studies suggest that there are no differences in levels of physical activity between individuals who have chronic pain when compared to healthy, age-matched controls $[35,38]$. It is 
difficult to determine from these studies if the subjects had increased levels of fear avoidance, pain catastrophisation or self-perceptions of disability, however most of these studies were cross-sectional in design. There is a dearth of literature that examines short term changes in objectively measured PA when physical therapy interventions, particularly spinal manipulations, exercise and patient education are administered to these individuals. Studies are needed to quantify if there is an effect of these commonly used physical therapy interventions on freeliving physical activity for individuals with CLBP. Freeliving physical activity is defined as "the level of activity that the patients, within their physical limitations, at their own pace, and in their own environment, typically perform [46]".

A pilot study was conducted to examine the effects of physical therapy interventions for individuals with CLBP based on the aim to quantify the short-term effects of one PT session that included spinal manipulations, exercise and patient education on free-living PA in individuals with CLBP. This combination of interventions represents a "typical" initial physical therapy session of individuals with CLBP. We hypothesize that the additive effects of each intervention will have the capacity to have an immediate increase in free-living physical activity. The purpose of this pilot study was to determine effect sizes that may be used to establish sample sizes for future studies that investigate the efficacy of physical therapy interventions to increase physical activity in persons with CLBP.

\section{Methods}

Subjects were recruited from a publicly funded, hospitalbased outpatient physical therapy clinic. The inclusion criteria were: (1) patient referral to outpatient PT with a CLBP related diagnosis; (2) CLBP without radiating pain distally to the knee $>3$ months in duration; (3) ability to read and write in English or Spanish; and (4) between the ages of 18 and 70 years old; (5) able to ambulate independently without assistive devices. Subjects were excluded if they had: (1) previously been diagnosed via radiography or clinical exam with spinal instability, fracture or tumor; (2) a clinical indication of nerve root pathology; (3) previous spinal surgery; (4) a diagnosis of osteoporosis or rheumatoid arthritis; (5) used oral steroids within the previous 6 months; (6) a workman's compensation or disability claim filed for a previous low back injury; (7) self-report of current or suspected pregnancy; and (8) presented with incomplete accelerometer data. All subjects completed an informed consent document prior to enrollment into the study that was approved by the Institutional Review Board of Texas Woman's University and Harris Health Systems.

\section{Outcome measures}

Physical activity Triaxial accelerometers [GT3XP-BTLE; Actigraph, LLC., FL, USA] were used to measure the physical activity level of the subjects at a frequency of $30 \mathrm{~Hz}$. This is a small device with dimensions that are $4.6 \mathrm{~cm} \times 3.3 \mathrm{~cm} \times 1.5 \mathrm{~cm}$, that weighs $19 \mathrm{~g}$. The inclinometer within these accelerometers was also activated to measure time spent in sitting, standing or recumbent postures. The accelerometers were activated within the Actilife software [v6.0; Actigraph, FL, USA] using each subject's weight, height, race/ethnicity, sex, date of birth, and hand dominance. The means of the following parameters were the variables of interest for this study: (1) number of steps taken each day; (2) mean percentage of the day spent performing sedentary (SED) [(0-99 counts), light (LHT) (100-1951 counts), moderate-tovigorous physical activity (MVPA) ( $\geq 1952$ counts) each day; 3] mean percentage of the day spent in the standing, lying and sitting positions. The Actigraph accelerometer has excellent reliability and validity with other methods for assessing energy expenditures across varied levels of physical activity [47]. The subjects were instructed to wear the accelerometer on the right hip during their waking hours for at least $8 \mathrm{~h}$ for a period of 7 days. Instances where the accelerometer did not reach values higher than zero counts within a 10-min epoch were considered as non-wear time. If the data for each subject did not reach the pre-established wear time of at least 3-days, then the data for this subject was removed from the analysis. Therefore, in order to consider data valid for analysis, each subject needed to have at least $5 \mathrm{~h} /$ day of wear time for at least 3 days during the 7-day period, regardless of whether the days were consecutive or not. Three days of accelerometry data has been suggested in other studies to be the minimal wear time to reliably capture physical activity patterns in adults [48-50]. The percentage of time spent performing SED, LHT and MVPA per day were calculated with the Freedson 1998 algorithms [51].

\section{Study protocol}

Six physical therapists participated in this study. Their clinical experience ranged from 2 to 8 years. All of them received advanced training in orthopedic manual physical therapy with a patient caseload comprised of approximately $90-95 \%$ orthopedic disorders with approximately $50 \%$ of those patients referred to physical therapy with low back pain. Patients were referred to the outpatient physical therapy clinic to be evaluated for their primary complaint of low back pain. During this process, eligibility for inclusion into the study was assessed by the physical therapist assigned to the patient. If the patient was found eligible for inclusion in the study, he or she was invited 
to participate in the study; all patients who accepted the invitation then completed the informed consent process. The first session included data collection only, with no treatment intervention conducted during this session. To obtain baseline data, each subject was asked to wear the accelerometer for the next seven consecutive days for at least $8 \mathrm{~h} /$ day. Each subject was scheduled for their first treatment session one week after the initial evaluation to allow for one full week of PA data capture utilizing the accelerometer. At the first treatment session, the accelerometer was retrieved and the data downloaded onto a designated research computer via ActiLife ${ }^{\circledR}$ software. To ensure adequate retrieval of the accelerometer, subjects who missed the first treatment session were either called or emailed to reschedule the appointment. Subjects who returned for the first treatment session without the accelerometer were asked to bring it to the next treatment session; the data was analyzed using only the initial 7 days from the day of issue. If a subject did not: (1) return the accelerometer; (2) return it with adequate data; (3) return for a scheduled physical therapy session; and (4) respond to the text, email or phone messages, then the patient was considered lost to follow-up.

The physical therapy intervention was based on a previously published clinical guideline on the management of low back pain [8]. The physical therapy intervention consisted of one treatment session that included a manipulation technique(s) to either the sacroiliac joint, thoracic, or lumbar spine. The manual therapy interventions are described below and pictures and descriptions of the manual therapy interventions can be found in Additional file 1: Appendix S1.

1. Thoracic gapping manipulation: a high-velocity, low amplitude end-range technique was delivered using an anterior-posterior directed thrust at the mid and lower thoracic spine using the patient's crossed arms and flexed elbows.

2. Lumbopelvic gapping manipulation: a high-velocity, low-amplitude end-range thrust technique was delivered using an anterior-inferior directed thrust applied to the flexed lumbar spine in a side-lying position.

3. Lumbopelvic unilateral gapping mobilizations: a mid to end-range, non-thrust mobilization technique applied to lumbar spine in side-lying using an anterior-lateral directed force with the individual's cranial hip flexed.

4. Hip long-axis distraction manipulation: a high-velocity, end-range thrust technique applied in an axial direction through the distal lower extremity to the flexed, abducted and slightly externally-rotated hip joint in supine.
Each subject was instructed on an exercise program based on the clinical judgement of the physical therapist that are classified as motor control exercises, transversus abdominis training, lumbar multifidus training, and dynamic lumbar stabilization exercises based on the published clinical guidelines by [8]. The primary exercises included were: (1) quadruped heel rocks, supine abdominal brace and bent knee fallout exercises to enhance motor control, recruitment of the transversus abdominis and multifidi; (2) chair stands, seated hip hinge, bridging were used to promote dynamic lumbar stabilization during functional movements. The pictures and descriptions of the exercises can be found in Additional file 1: Appendix S2. The sequence of how the manual therapy and exercise interventions were administered can be found in Additional file 1: Appendix S3.

These exercises were performed at the first treatment session and each patient was instructed in a home exercise program to promote increased segmental mobility and stability of the lumbar spine. Each subject performed a submaximal aerobic endurance exercise on either a bicycle, treadmill or elliptical trainer with the duration and intensity set at a moderate intensity level based on the effort that was verbally given to the therapist. Patient education was provided which consisted of techniques to promote self-management of his or her CLBP condition via cognitive behavioral approaches such as graded exercise, graded exposure or basic pain science information to minimize the hypervigilant behaviors such as restriction of certain activities [12, 13, 21]. At the conclusion of the first treatment session, each participant was issued the accelerometer for a second time and instructed to wear the device in a similar fashion for another 7 day period. Each subject was asked to return the accelerometer at their next treatment session, scheduled 7 days later.

\section{Data analysis}

The means and standard deviations (SD) for the following physical activity variables derived from the accelerometer were computed: number of steps taken each day, percentage of the day spent performing SED, LHT and MVPA per day (counts/day) and the percentage of the day spent in the sitting, lying and standing positions. Descriptive variables such as the mean age, height, weight, BMI and gender of the study participants were calculated. Cohen's $d$ was calculated to determine the baseline and post intervention effect size for the variables previously listed using the formula below:

$$
d=\frac{\text { Mean }_{\text {(baseline) }}-\text { Mean }_{\text {(post }- \text { intervention })}}{\mathrm{SD}_{(\text {pooled })}}
$$

The aim of this pilot study was to determine the effect size of one physical therapy session on physical activity 
levels, one-tailed paired $t$-tests were performed with the level of significance set at 0.05 determine if significant differences were found between the baseline and postintervention means for the aforementioned variables. One-tailed level of significance supports the hypothesis that the one session intervention will promote a decrease in the SED activities while promoting an increase in LHT and MVPA. Twenty-seven subjects were needed to achieve $80 \%$ power based on an a priori analysis using an effect size of 0.50 for 0.05 level of significance using onetail. The effect size used for the power analysis was based on a systematic review published by Keller et al. that examined the effects of interventions performed on individuals with chronic low back pain using self-perceptions of pain and function as the outcomes [52]. They reported pooled effect sizes of $0.57,0.52$ and 0.35 for behavioral interventions, exercise training and manipulation, respectively.

\section{Results}

Thirty subjects were screened for eligibility, with 27 subjects fully enrolled. After screening for validity of the accelerometer data, a total of 14 subjects' accelerometer, self-report and physical performance measures were analyzed (Fig. 1).

The 13 subjects that were not included in the analysis did not meet the required wear time of the accelerometer as previously discussed. There were 11 females and 3 males (7 African-Americans, 6 Hispanic, 1 Caucasian); the mean age and BMI was 50.2 years, $31.6 \mathrm{~kg} /$ $\mathrm{m}^{2}$, respectively. The physical activity measures and wear time of the accelerometer at baseline and post intervention are presented in Table 1.

There was a trend towards reduction in the number of steps taken per day and the time spent performing

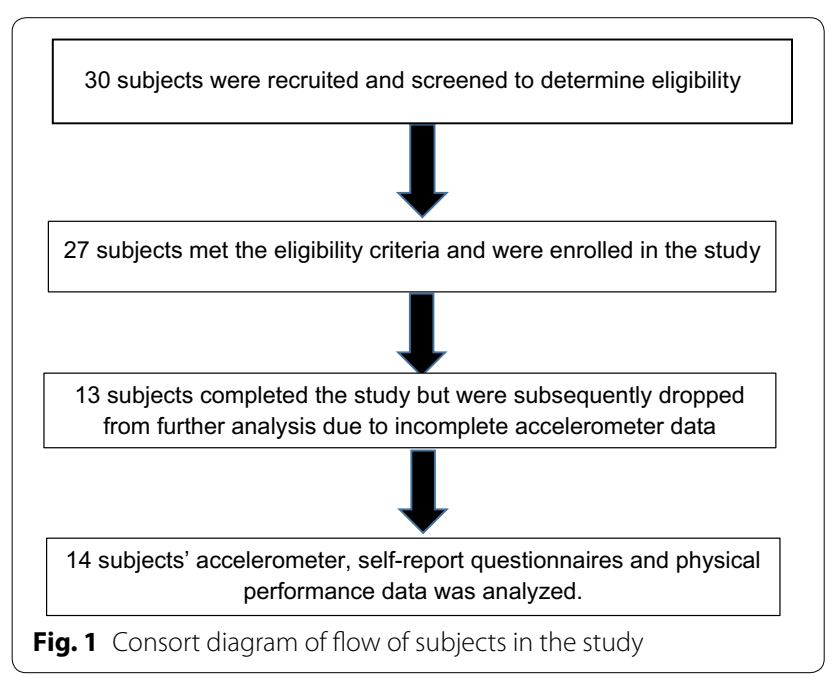

Table 1 Mean (S.D.) percentage of the day spent performing: sedentary, light, moderate-vigorous physical activities and standing, lying and sitting position

\begin{tabular}{lccll}
\hline & $\begin{array}{l}\text { Baseline, } \\
(\mathbf{n}=\mathbf{1 4})\end{array}$ & $\begin{array}{l}\text { Post-interven- } \\
\text { tion }\end{array}$ & $\begin{array}{l}\text { Effect } \\
\text { size }(\boldsymbol{d})\end{array}$ & $\boldsymbol{p}$-value \\
\hline Steps per day & $5735.1(3484.9)$ & $5205.7(3374.3)$ & 0.15 & 0.22 \\
SED (\%) & $62.1(9.5)$ & $59.0(10.9)$ & 0.31 & 0.12 \\
LHT (\%) & $35.7(8.2)$ & $38.5(9.1)$ & 0.33 & 0.13 \\
MVPA (\%) & $2.1(2.2)$ & $2.5(2.8)$ & 0.16 & 0.28 \\
Standing (\%) & $40.4(11.4)$ & $37.9(9.9)$ & 0.23 & 0.07 \\
Lying (\%) & $9.46(6.7)$ & $16.1(11.9)$ & 0.69 & 0.03 \\
Sitting (\%) & $50.1(10.8)$ & $46.0(13.0)$ & 0.34 & 0.11 \\
Wear time & $732.0(123.1)$ & $698.8(142.6)$ & & $0.395^{¥}$ \\
(min) & & & & \\
\hline Fenotes & & & &
\end{tabular}

¥ Denotes 2-tail analysis

SED activities, with concurrent increases in LHT and MVPA. These findings presented with small effect sizes that ranged from 0.33 and.16 for the percentage increase in time spent performing LHT and MVPA, respectively. The paired $\mathrm{t}$-tests revealed no post-intervention significant differences from baseline in physical activity levels (Table 1). A nonsignificant decrease in percentage of the day was spent sitting and standing during the 1 week immediately following the physical therapy session, with a concurrent significant increase in the percentage of the day spent lying $(p=0.03)$. The baseline to post-intervention effect sizes for the percentage of time spent in each position were small to medium and ranged from 0.23 to 0.69 (Table 1).

\section{Discussion}

The purpose of this pilot study was to determine the effect size that one session of PT has on physical activity. This pilot study showed that one session of PT that included spinal manipulation, exercise and patient education had a trend towards increasing physical activity for individuals with chronic low back pain. There was a small effect of reducing the percentage of time spent performing SED activities with a similar effect of increasing time spent performing light physical activities. Paradoxically, the percentage of time spent lying increased while the time spent standing and sitting decreased.

Researchers that conduct studies that examine the impact that PT has on free-living physical activities need to carefully consider their aims of their study to be adequately powered. If the aim of their study is to determine the impact that PT has on reducing time spent performing SED and increasing LHT physical activities for individuals with CLBP then the sample size requirements are approximately four times less than studies that seek adequate power to detect changes in MVPA. Despite 
MVPA being touted as the level of activity needed to promote health, studies that examine changes in this type of behavior must have the resources needed to support a large number of subjects to detect small changes in this behavior. It is evident that this drastic difference in sample size requirements stems from the fact that for individuals with CLBP, the majority of the time is spent performing SED activities which provides researchers a larger opportunity to study the effects of interventions to shift these individuals' physical activity levels towards the light intensity.

There are several limitations of the study that warrant discussion. The extremely small sample size limits the ability to make inferences to a larger population. This study was underpowered due to non-compliance with accelerometer wear time. Despite the increased risk of bias, the power analysis was based on previous effect sizes determined for pain and self-perceptions of function, which are variables not considered for this study. Because this is the first study to examine changes in physical activity levels after one physical therapy session, there were no established effect sizes that could be used to directly determine the sample size to be sufficiently powered. The subjects in this study were primarily female, whose ethnic backgrounds were predominately African-American or Hispanic, and who were seeking physical therapy services at a publicly-funded outpatient clinic. Previous studies suggest that leisure-time physical activity patterns tend to be lower for: men compared to women, minorities compared to Caucasians, and individuals with lower as compared to those of higher socioeconomic status $[53,54]$. The results in this population may not be consistent with those observed in other populations. Lastly, causation would have been more evident with the addition of a control group using a mixed between and within subjects design, however the present design did allow for each subject to be his or her own control. Future studies that examine the impact of physical therapy on physical activities patterns need to utilize larger, more ethnically diverse sample sizes with individuals of varied socioeconomic levels with longer follow-up periods.

\section{Conclusion}

There have been numerous studies that have examined the short-term effects of physical therapy interventions on the understanding of pain neurophysiology, self-reported pain, disability and biomechanics. To our knowledge, this is the first study to determine the effect size of a single physical therapy session that includes exercise, patient education and spinal manipulation on changes in physical activity profiles for individuals with CLBP. The generation of these effects sizes will allow future researchers to determine adequate sample sizes needed to answer additional research questions regarding the impact of physical therapy on physical activity. A comprehensive physical therapy program results in a small effect to increase the level of physical activity in individuals with CLBP as soon as the first treatment session.

\section{Additional files}

Additional file 1: Appendix S1. Lumbopelvic manipulation techniques.

Additional file 2: Appendix S2. Lumbar stabilization and range of motion exercise program.

Additional file 3: Appendix S3. Physical therapy treatment sequence.

\section{Abbreviations}

LBP: Iow back pain; CLB: chronic low back pain; PT: physical therapy; PA: physical activity; SED: sedentary; LHT: light; MVPA: moderate-vigorous physical activity.

\section{Authors' contributions}

WB: provided the initial conceptual design, drafted the manuscript, secured the data collection site and funding to conduct the study. BS and TR: provided initial and revised conceptual design, review and substantial revision of the manuscript, composed the background and methods section of the manuscript. HA, CA, JF, CP: provided data acquisition, implemented the study procedures, recruitment of subjects, composed the study intervention description of the methods section of the manuscript, provided manuscript review, provided pictures at the data collection sites. AO: provided initial and revised conceptual design, data analysis, composed the accelerometry data acquisition process under the methods section of the manuscript, manuscript revision and interpretation of accelerometry data in the discussion section of the manuscript. All authors read and approved the final manuscript.

\section{Author details}

${ }^{1}$ Texas Woman's University, 6124 Institute of Health Sciences-Houston, 7600 Fannin Street, Houston, TX 77030, USA. ${ }^{2}$ University of New England, Portland, ME, USA. ${ }^{3}$ Texas Woman's University, Houston, TX, USA. ${ }^{4}$ Harris Health Systems, Houston, TX, USA.

\section{Acknowledgements}

The authors would like to thank Dr. Dana Tew, manager of outpatient rehabilitation services and Dr. Christopher Dewey, director of rehabilitation services of Harris Health, Quentin Mease Rehabilitation Hospital for providing managerial and administrative support for this project.

\section{Competing interests}

The authors declare that they have no competing interests.

\section{Availability of data and materials}

The datasets during and/or analyzed during the current study available from the corresponding author on reasonable request.

\section{Consent for publication}

Not applicable.

\section{Ethics approval and consent to participate}

All subjects who participated in this study gave prior written and verbal consent. Ethical approval for the study procedures were obtained from Texas Woman's University Institutional Review Board (Protocol: 17852).

\section{Funding}

This study was supported by grant funds furnished by the Texas Woman's University Research Enhancement Program (11.410.10.1221.00002264).

Funding to publish this study was provided by the Texas Woman's University Library Open Access Fund. 


\section{Publisher's Note}

Springer Nature remains neutral with regard to jurisdictional claims in published maps and institutional affiliations.

Received: 27 October 2016 Accepted: 28 November 2017 Published online: 06 December 2017

\section{References}

1. Freburger JK, Holmes GM, Agans RP, Jackman AM, Darter JD, Wallace AS, Castel LD, Kalsbeek WD, Carey TS. The rising prevalence of chronic low back pain. Arch Intern Med. 2009;169(3):251-8.

2. Hoy D, Brooks P, Blyth F, Buchbinder R. The Epidemiology of low back pain. Best Pract Res Clin Rheumatol. 2010;24(6):769-81.

3. Wertli MM, Rasmussen-Barr E, Weiser S, Bachmann LM, Brunner F. The role of fear avoidance beliefs as a prognostic factor for outcome in patients with nonspecific low back pain: a systematic review. Spine J. 2014;14(5):816-36.

4. Guclu DG, Guclu O, Ozaner A, Senormanci O, Konkan R. The relationship between disability, quality of life and fear-avoidance beliefs in patients with chronic low back pain. Turk Neurosurg. 2012;22(6):724-31.

5. Koes BW, van Tulder MW, Thomas S. Diagnosis and treatment of low back pain. BMJ. 2006;332(7555):1430-4.

6. Vlaeyen JW, Linton SJ. Fear-avoidance and its consequences in chronic musculoskeletal pain: a state of the art. Pain. 2000;85(3):317-32.

7. Vlaeyen JW, Kole-Snijders AM, Boeren RG, van Eek H. Fear of movement/ (re)injury in chronic low back pain and its relation to behavioral performance. Pain. 1995;62(3):363-72.

8. Delitto A, George SZ, Van Dillen LR, Whitman JM, Sowa G, Shekelle P, Denninger TR, Godges JJ. Orthopaedic section of the American Physical Therapy Association: low back pain. J Orthop Sports Phys Ther. 2012;42(4):A1-57.

9. Delitto A, Erhard RE, Bowling RW. A treatment-based classification approach to low back syndrome: identifying and staging patients for conservative treatment. Phys Ther. 1995;75(6):470-85.

10. Stanton TR, Fritz JM, Hancock MJ, Latimer J, Maher CG, Wand BM, Parent EC. Evaluation of a treatment-based classification algorithm for low back pain: a cross-sectional study. Phys Ther. 2011;91(4):496-509.

11. Stanton TR, Hancock MJ, Apeldoorn AT, Wand BM, Fritz JM. What characterizes people who have an unclear classification using a treatment based classification algorithm for low back pain? A cross-sectional study. Phys Ther. 2013;93(3):345-55.

12. George SZ, Wittmer VT, Fillingim RB, Robinson ME. Comparison of graded exercise and graded exposure clinical outcomes for patients with chronic low back pain. J Orthop Sports Phys Ther. 2010;40(11):694-704.

13. George SZ, Zeppieri G. Physical therapy utilization of graded exposure for patients with low back pain. J Orthop Sports Phys Ther. 2009:39(7):496-505

14. Rubinstein SM, van Middelkoop M, Assendelft WJ, de Boer MR, van Tulder MW. Spinal manipulative therapy for chronic low-back pain. Cochrane Database Syst Rev. 2011;2:CD008112.

15. Swenson R, Haldeman S. Spinal manipulative therapy for low back pain. J Am Acad Orthop Surg. 2003;11(4):228-37.

16. Bronfort G, Haas M, Evans RL, Bouter LM. Efficacy of spinal manipulation and mobilization for low back pain and neck pain: a systematic review and best evidence synthesis. Spine J. 2004;4(3):335-56.

17. Borys C, Lutz J, Strauss B, Altmann U. Effectiveness of a multimodal therapy for patients with chronic low back pain regarding pre-admission healthcare utilization. PLOS ONE. 2015;10(11):e0143139.

18. Campbell J, Colvin LA. Management of low back pain. BMJ. 2013:347:f3148

19. Chou R, Qaseem A, Owens DK, Shekelle P. Clinical Guidelines Committee of the American College of Physicians: diagnostic imaging for low back pain: advice for high-value health care from the American College of Physicians. Ann Intern Med. 2011;154(3):181-9.

20. Last AR, Hulbert K. Chronic low back pain: evaluation and management. Am Fam Physician. 2009;79(12):1067-74.
21. Louw A, Diener I, Butler DS, Puentedura EJ. The effect of neuroscience education on pain, disability, anxiety, and stress in chronic musculoskeletal pain. Arch Phys Med Rehabil. 2011;92(12):2041-56.

22. Leeuw M, Goossens ME, Linton SJ, Crombez G, Boersma K, Vlaeyen JW. The fear-avoidance model of musculoskeletal pain: current state of scientific evidence. J Behav Med. 2007;30(1):77-94.

23. Kovacs F, Abraira V, Santos S, Diaz E, Gestoso M, Muriel A, Gil del Real MT, Mufraggi N, Noguera J, Zamora J. Spanish Back Pain Research Network: a comparison of two short education programs for improving low back pain-related disability in the elderly: a cluster randomized controlled trial. Spine (Phila Pa 1976). 2007:32(10):1053-9.

24. Albaladejo C, Kovacs FM, Royuela A, del Pino R, Zamora J. Spanish Back Pain Research Network: the efficacy of a short education program and a short physiotherapy program for treating low back pain in primary care: a cluster randomized trial. Spine (Phila Pa 1976). 2010;35(5):483-96.

25. Smeets RJ, Vlaeyen JW, Hidding A, Kester AD, van der Heijden GJ, van Geel AC, Knottnerus JA. Active rehabilitation for chronic low back pain: cognitive-behavioral, physical, or both? First direct post-treatment results from a randomized controlled trial [ISRCTN22714229. BMC Musculoskelet Disord. 2006;7:5.

26. Rutledge T, Atkinson JH, Chircop-Rollick T, D'Andrea J, Garfin S, Patel S, Penzien DB, Wallace M, Weickgenant AL, Slater M. Randomized controlled trial of telephone-delivered cognitive behavioral therapy versus supportive care for chronic back pain. Clin J Pain. 2017. https://doi.org/10.1097/ AJP.0000000000000555.

27. Luk KD, Wan TW, Wong YW, Cheung KM, Chan KY, Cheng AC, Kwan MW, Law KK, Lee PW, Cheing GL. A multidisciplinary rehabilitation programme for patients with chronic low back pain: a prospective study. J Orthop Surg (Hong Kong). 2010;18(2):131-8.

28. George SZ, Valencia C, Beneciuk JM. A psychometric investigation of fear-avoidance model measures in patients with chronic low back pain. J Orthop Sports Phys Ther. 2010;40(4):197-205.

29. Maughan EF, Lewis JS. Outcome measures in chronic low back pain. Eur Spine J. 2010;19(9):1484-94

30. Huijnen I, Verbunt J, Wittink H, Smeets J. Physical performance measurement in chronic low back pain: measuring physical capacity or painrelated behaviour? Eur J Physiother. 2013;15(3):103-10.

31. Plaas H, Sudhaus S, Willburger R, Hasenbring MI. Physical activity and low back pain: the role of subgroups based on the avoidance-endurance model. Disabil Rehabil. 2014:36(9):749-55.

32. Alschuler KN, Hoodin F, Murphy SL, Rice J, Geisser ME. Factors contributing to physical activity in a chronic low back pain clinical sample: a comprehensive analysis using continuous ambulatory monitoring. Pain. 2011:152(11):2521-7.

33. van Weering MG, Vollenbroek-Hutten MM, Hermens HJ. The relationship between objectively and subjectively measured activity levels in people with chronic low back pain. Clin Rehabil. 2011;25(3):256-63.

34. Hendrick P, Milosavljevic S, Bell ML, Hale L, Hurley DA, McDonough SM, Melloh M, Baxter DG. Does physical activity change predict functional recovery in low back pain? Protocol for a prospective cohort study. BMC Musculoskelet Disord. 2009:10:136.

35. van Weering MG, Vollenbroek-Hutten MM, Tonis TM, Hermens HJ. Daily physical activities in chronic lower back pain patients assessed with accelerometry. Eur J Pain. 2009;13(6):649-54

36. Hasenbring MI, Plaas H, Fischbein B, Willburger $\mathrm{R}$. The relationship between activity and pain in patients 6 months after lumbar disc surgery: do pain-related coping modes act as moderator variables? Eur J Pain. 2006;10(8):701-9.

37. Liszka-Hackzell JJ, Martin DP. An analysis of the relationship between activity and pain in chronic and acute low back pain. Anesth Analg. 2004;99(2):477-81.

38. Verbunt JA, Westerterp KR, van der Heijden GJ, Seelen HA, Vlaeyen JW, Knottnerus JA. Physical activity in daily life in patients with chronic low back pain. Arch Phys Med Rehabil. 2001;82(6):726-30.

39. Gomersall SR, Ng N, Burton NW, Pavey TG, Gilson ND, Brown WJ. Estimating physical activity and sedentary behavior in a free-living context: a pragmatic comparison of consumer-based activity trackers and ActiGraph accelerometry. J Med Internet Res. 2016;18(9):e239.

40. Troiano RP. Large-scale applications of accelerometers: new frontiers and new questions. Med Sci Sports Exerc. 2007:39(9):1501. 
41. Crouter SE, Churilla JR, Bassett DR Jr. Estimating energy expenditure using accelerometers. Eur J Appl Physiol. 2006;98(6):601-12.

42. Vanhees L, Lefevre J, Philippaerts R, Martens M, Huygens W, Troosters T, Beunen $\mathrm{G}$. How to assess physical activity? How to assess physical fitness? Eur J Cardiovasc Prev Rehabil. 2005;12(2):102-14.

43. Prince SA, Adamo KB, Hamel ME, Hardt J, Connor Gorber S, Tremblay M. A comparison of direct versus self-report measures for assessing physical activity in adults: a systematic review. Int J Behav Nutr Phys Act. 2008;5:56.

44. Downs A, Van Hoomissen J, Lafrenz A, Julka DL. Accelerometer-measured versus self-reported physical activity in college students: implications for research and practice. J Am Coll Health. 2014;62(3):204-12.

45. Dyrstad SM, Hansen BH, Holme IM, Anderssen SA. Comparison of self-reported versus accelerometer-measured physical activity. Med Sci Sports Exerc. 2014;46(1):99-106.

46. Moy ML, Matthess K, Stolzmann K, Reilly J, Garshick E. Free-living physical activity in COPD: assessment with accelerometer and activity checklist. J Rehabil Res Dev. 2009;46(2):277-86.

47. Aadland E, Ylvisaker E. Reliability of the actigraph GT3X+ accelerometer in adults under free-living conditions. PLoS ONE. 2015;10(8):e0134606.

48. Hart TL, Swartz AM, Cashin SE, Strath SJ. How many days of monitoring predict physical activity and sedentary behaviour in older adults? Int J Behav Nutr Phys Act. 2011;8:62.
49. Schuelter-Trevisol F, Wolff FH, Alencastro PR, Grigoletti S, Ikeda ML, Brandao AB, Barcellos NT, Fuchs SC. Physical activity: do patients infected with HIV practice? How much? A systematic review. Curr HIV Res. 2012;10(6):487-97.

50. Qi Q, Strizich G, Merchant G, Sotres-Alvarez D, Buelna C, Castaneda SF, Gallo LC, Cai J, Gellman MD, Isasi CR, Moncrieft AE, Sanchez-Johnsen L, Schneiderman N, Kaplan RC. Objectively measured sedentary time and cardiometabolic biomarkers in US hispanic/latino adults: the hispanic community health study/study of latinos (HCHS/SOL). Circulation. 2015;132(16):1560-9.

51. Freedson PS, Lyden K, Kozey-Keadle S, Staudenmayer J. Evaluation of artificial neural network algorithms for predicting METs and activity type from accelerometer data: validation on an independent sample. J Appl Physiol. 2011;111(6):1804-12.

52. Keller A, Hayden J, Bombardier C, van Tulder M. Effect sizes of nonsurgical treatments of non-specific low-back pain. Eur Spine J. 2007;16(11):1776-88

53. Saffer H, Dave D, Grossman M, Leung LA. Racial, ethnic, and gender differences in physical activity. J Hum Cap. 2013;7(4):378-410.

54. Marshall SJ, Jones DA, Ainsworth BE, Reis JP, Levy SS, Macera CA. Race/ ethnicity, social class, and leisure-time physical inactivity. Med Sci Sports Exerc. 2007:39(1):44-51.

\section{Submit your next manuscript to BioMed Central and we will help you at every step:}

- We accept pre-submission inquiries

- Our selector tool helps you to find the most relevant journal

- We provide round the clock customer support

- Convenient online submission

- Thorough peer review

- Inclusion in PubMed and all major indexing services

- Maximum visibility for your research

Submit your manuscript at www.biomedcentral.com/submit 